\title{
Chitosan/poly(2-ethyl-2-oxazoline) films for ocular drug delivery: Formulation, miscibility, in vitro and in vivo studies
}

Article

Accepted Version

Abilova, G. K., Kaldybekov, D. B., Ozhmukhametova, E. K., Saimova, A. Z., Kazybayeva, D. S., Irmukhametova, G. S. and Khutoryanskiy, V. V. (2019) Chitosan/poly(2-ethyl-2-oxazoline) films for ocular drug delivery: Formulation, miscibility, in vitro and in vivo studies. European Polymer Journal, 116. pp. 311320. ISSN 0014-3057 doi:

https://doi.org/10.1016/j.eurpolymj.2019.04.016 Available at https://centaur.reading.ac.uk/83324/

It is advisable to refer to the publisher's version if you intend to cite from the work. See Guidance on citing.

Published version at: https://www.sciencedirect.com/science/article/pii/S0014305719303313

To link to this article DOI: http://dx.doi.org/10.1016/j.eurpolymj.2019.04.016

Publisher: Elsevier

All outputs in CentAUR are protected by Intellectual Property Rights law, including copyright law. Copyright and IPR is retained by the creators or other copyright holders. Terms and conditions for use of this material are defined in the End User Agreement. 


\section{CentAUR}

Central Archive at the University of Reading

Reading's research outputs online 
1 Chitosan/poly(2-ethyl-2-oxazoline) films for ocular drug delivery:

3 Guzel K. Abilova, ${ }^{a}$ Daulet B. Kaldybekov, ${ }^{\text {a,b }}$ Elvira K. Ozhmukhametova, ${ }^{c}$ Aisulu Zh. Saimova, ${ }^{c}$

4 Diara S. Kazybayeva, ${ }^{\mathrm{a}}$ Galiya S. Irmukhametova, ${ }^{\mathrm{a}}$ Vitaliy V. Khutoryanskiy ${ }^{\mathrm{b}, *}$

5 a Department of Chemistry and Chemical Technology, Al-Farabi Kazakh National University,

6050040 Almaty, Kazakhstan

$7 \quad{ }^{b}$ School of Pharmacy, University of Reading, Whiteknights, RG6 6AD Reading, United Kingdom

$8 \quad{ }^{c}$ Semey State Medical University, 071400 Semey, Kazakhstan

9

10

11

12

13

14

15

16

17

18

19

*Corresponding author:

Postal address: School of Pharmacy, University of Reading, Whiteknights, PO Box 224, RG6 6AD

Reading, United Kingdom

E-mail address: v.khutoryanskiy@ reading.ac.uk

Telephone: +44(0) 1183786119

Fax: +44(0) 1183784703 


\section{ABSTRACT}

Polymeric films were prepared based on chitosan and its blends with poly(2-ethyl-2-oxazoline) by casting from aqueous solutions. These materials were characterised using a number of physicochemical techniques, including Fourier-transform infrared spectroscopy, thermal gravimetric analysis, differential scanning calorimetry, wide angle x-ray diffraction, tensile testing and scanning electron microscopy. All these studies indicate that there is a weak intermacromolecular hydrogen bonding between these polymers, which facilitates their complete miscibility in solid state. These films were formulated with sodium fluorescein as a model drug and were evaluated for their potential application in ocular drug delivery both in vitro and in vivo. It was established that the films are biocompatible and mucoadhesive; they are capable of providing a sustained drug release when administered topically on the cornea.

Keywords: chitosan, poly(2-oxazoline), films, miscibility, mucoadhesion, ocular drug delivery

\section{INTRODUCTION}

Ability of hydrophilic polymers to stick to wet surfaces in the human body, defined as mucoadhesion, has been widely used for designing dosage forms for transmucosal administration. The current applications of mucoadhesive dosage forms include drug delivery to the eye, nose, oral cavity, gastrointestinal tract, vagina, rectum and urinary bladder [1-5]. These routes of drug administration offer a number of advantages and the use of mucoadhesive carriers facilitates better dosage form retention on mucosal surfaces resulting in improved drug bioavailability, possibility of targeting particular organs, ease of application and avoidance of painful injections.

Typically, all water-soluble polymers have some mucoadhesive properties; however, either positively or negatively charged polyelectrolytes exhibit better ability to stick to mucosal tissues compared to non-ionic macromolecules [2]. Chitosan as a polysaccharide of cationic nature is considered as one of the materials with excellent mucoadhesive properties and its numerous 
applications in transmucosal drug delivery have been demonstrated [6-8]. Many attempts have been reported to modify mucoadhesive properties of chitosan through its chemical modification, as discussed in a recent review by Ways et al [9]. Additionally, properties of chitosan could also be altered by simple blending with other polymers. For example, Luo et al [10] demonstrated that chitosan forms miscible blends with hydroxyethylcellulose, which resulted in reduction of mucoadhesive properties of the buccal films based on the mixtures of these polymers. Freag et al [11] reported the development of mucoadhesive sponges based on blends of chitosan with hydroxypropylmethylcellulose and demonstrated that the materials prepared from 1:1 polymer mixture exhibited the best physicochemical characteristics suitable for buccal administration. Sizílio et al [12] fabricated mucoadhesive films by blending chitosan with poly(N-vinyl pyrrolidone) and evaluated their application for delivery of betamethasone-17-valerate used in the therapy of recurrent aphthous stomatitis.

Poly(2-oxazolines) is an emerging class of polymers highly promising for biomedical applications due to their non-toxicity, bio-inert nature and unique physicochemical properties [1317]. Water-soluble representatives of this class such as poly(2-methyl-2-oxazoline), poly(2-ethyl-2oxazoline), and poly(N-propyl-2-oxazoline) have received a lot of attention of researchers due to their unique physicochemical properties such as the ability to form hydrogen-bonded complexes with polycarboxylic acids and tannins [18-20] as well as their temperature-responsive properties [21]. Due to their bio-inert nature, low molecular weight poly(2-methyl-2-oxazoline) and poly(2-ethyl-2oxazoline) $(5 \mathrm{kDa})$ were reported to facilitate mucus-penetration of silica nanoparticles through porcine stomach mucosa [22,23] and to reduce their mucoadhesion to rat intestinal tissues [24]. Poly(2-ethyl-2-oxazolines) with larger molecular weights (50, 200 and $500 \mathrm{kDa})$ exhibited weak mucoadhesive properties and their simple blends and complexes with Carbopols 971 and 974 also resulted in reduction of dosage forms mucoadhesiveness compared to pure Carbopols ${ }^{\circledR}$ [25].

Polymer blending and miscibility of poly(2-oxazolines) with other polymers is studied insufficiently. Earlier publications reported the miscibility studies of poly(2-oxazolines) with 
hydroxyl-containing polymers [26-28] and some conventional plastic materials such as poly(vinyl chloride), polystyrene, polypropylene and poly(vinylidene fluoride) [29]. Despite the growing biomedical importance of both chitosan and poly(2-oxazolines) the studies of miscibility in their blends are limited only to a very few publications [30].

In the present work we have prepared chitosan/poly(2-ethyl-2-oxazoline) films by casting from aqueous mixtures of these polymers; studied the physicochemical properties of these blends using Fourier transform infrared spectroscopy, thermal analysis and X-ray diffraction methods, tensile properties, and scanning electron microscopy; and evaluated the mucoadhesive potential and retention of these films on freshly excised bovine cornea ex vivo and on rabbit ocular cornea in vivo.

\section{EXPERIMENTAL SECTION}

\subsection{Materials}

A high molecular weight chitosan $\left(\mathrm{CHI}, \mathrm{M}_{\mathrm{W}} \sim 310-375 \mathrm{kDa}\right.$, degree of deacetylation: 75 85\%), poly(2-ethyl-2-oxazoline) (POZ, $\mathrm{M}_{\mathrm{W}} \sim 50 \mathrm{kDa}$ and PDI $3-4$ ), hydrochloric acid solution $(\mathrm{HCl}, 1 \mathrm{M})$, fluorescein sodium salt $(\mathrm{NaFl})$ and phosphate buffered saline (PBS) tablets were purchased from Sigma-Aldrich (Gillingham, UK). All other chemicals were of analytical grade and used without further purification.

\subsection{Preparation of films}

Chitosan solution was prepared by first dissolving $3.75 \mathrm{~g}$ of chitosan in $25 \mathrm{~mL}$ of $1 \mathrm{M} \mathrm{HCl}$, then the total volume was made up to $500 \mathrm{~mL}$ with deionised water $(\mathrm{CHI} 0.75 \% \mathrm{w} / \mathrm{v}, \mathrm{pH} \sim 4.0)$ and stirred magnetically overnight at room temperature. Before casting CHI solution was sonicated in a sonication bath (FS200b, Decon Laboratories Ltd., UK) for $30 \mathrm{~min}$. Poly(2-ethyl-2-oxazoline) solutions $(0.75 \% \mathrm{w} / \mathrm{v})$ were prepared by dissolving $3.75 \mathrm{~g}$ polymer powder in $500 \mathrm{~mL}$ of deionised water $(\mathrm{pH} \sim 6.8)$ for $1 \mathrm{~h}$ under continuous stirring. The film-forming solutions (FFS) with and without $\mathrm{NaFl}(0.1 \mathrm{mg} / \mathrm{mL})$ were obtained by mixing $\mathrm{CHI}$ and POZ aqueous solutions at different volume ratios, where part of $\mathrm{CHI}$ was gradually replaced with $\mathrm{POZ}$, up to $60 \%$. Formulations were named 
indicating the CHI/POZ volume ratio as CHI (100), (80:20), (60:40), (40:60) and POZ (100), respectively. The $\mathrm{pH}$ values of combined solutions were in the range of $4.0-4.2$. FFS were magnetically stirred for $3 \mathrm{~h}$ until fully homogeneous mixture formed, after that, $45 \mathrm{~mL}$ of each solution was poured into $90 \mathrm{~mm}$ diameter Petri dishes and dried at room temperature for several days.

\subsection{Fourier transform infrared (FTIR) spectroscopy}

FTIR spectra were recorded on Nicolet iS5 FTIR spectrometer (Thermo Scientific, UK) using an attenuated total reflectance (ATR) accessory equipped with a diamond crystal. The transmission mode was used and the resolution was $1 \mathrm{~cm}^{-1}$.

\subsection{Thermogravimetric analysis (TGA)}

Thermogravimetric analysis of $\mathrm{CHI}, \mathrm{POZ}$ and $\mathrm{CHI} / \mathrm{POZ}$ blend film samples was conducted using Q50 TGA analyser (TA Instruments, UK) in the range between 20 and $600{ }^{\circ} \mathrm{C}$ at a heating rate of $10{ }^{\circ} \mathrm{C} / \mathrm{min}$ under nitrogen atmosphere. Moisture content in each film was determined from the weight loss corresponding to the first step weight loss in their TGA curves (up to about $150{ }^{\circ} \mathrm{C}$ ).

\subsection{Differential scanning calorimetry (DSC)}

Differential scanning calorimetry (DSC) measurements were performed on TA-Q2000 DSC instrument (TA Instruments, UK). DSC thermograms of each film were recorded from the second heating run at $20{ }^{\circ} \mathrm{C} / \mathrm{min}$, after the first run of heating up to $80{ }^{\circ} \mathrm{C}$ and cooling down to $25^{\circ} \mathrm{C}$ at 10 ${ }^{\circ} \mathrm{C} / \mathrm{min}$, under nitrogen atmosphere, in order to estimate the glass transition temperatures $(\mathrm{Tg})$.

\subsection{X-Ray diffraction (XRD)}

X-Ray diffraction patterns of the polymers and their blends were evaluated using Oxford Diffraction Gemini Ultra diffractometer fitted with $\mathrm{CuK} \alpha$ radiation and Saturn detector (Oxford Diffraction Ltd., UK). Film samples were cut in $1 \times 1 \mathrm{~cm}$, loaded, and scanned at diffraction ranges from 6 to $120^{\circ}$ with a scan step of $0.01^{\circ}$, generating characteristic diffractograms at the rate of 2.5 scans $\min ^{-1}$. 


\subsection{Scanning electron microscope (SEM)}

SEM experiments used a FEI Quanta 600 FEG Environmental Scanning Electron Microscope instrument (FEI UK Ltd., UK) with an acceleration voltage of $20 \mathrm{kV}$. The images were taken from the fracture surface of the materials, which were preliminary frozen in liquid nitrogen and coated with gold sputter to facilitate high resolution imaging.

\subsection{Mechanical analysis}

Puncture strength (PS) and elongation at break (EB) of the films were measured using a TA.XT Plus Texture Analyser (Stable Micro Systems Ltd., UK) in compression mode at room temperature [31,32]. Film thickness was measured with a hand-held micrometer; six replicates were taken for each sample in different places and the mean values were calculated accordingly. The thickness of the films was about $0.065 \pm 0.002 \mathrm{~mm}$. The square shaped film samples $(30 \times 30 \mathrm{~mm})$ fixed by screws between two plates with a cylindrical hole of $10 \mathrm{~mm}$ diameter (area of the sample holder hole: $\operatorname{Ar}_{\mathrm{s}}=$ $\left.78.54 \mathrm{~mm}^{2}\right)$ and compressed by the upper load $5 \mathrm{~mm}$ stainless steel spherical ball probe (P/5S) at a test speed $1.0 \mathrm{~mm} / \mathrm{sec}$. The plate was stabilised to avoid movements using two pins. The measurements started after the probe was in contact with the sample surface. The probe moved at a constant speed until each film sample was broken [33]. These tests were performed with the following settings: pre-speed test $2.0 \mathrm{~mm} / \mathrm{sec}$; test-speed $1.0 \mathrm{~mm} / \mathrm{sec}$; post-test speed $10.0 \mathrm{~mm} / \mathrm{sec}$; target mode - distance; distance $5 \mathrm{~mm}$; trigger type auto; trigger force $0.049 \mathrm{~N}$. The film samples were punctured and the force required in Newtons was recorded and puncture strength was calculated using the following equation $[33,34]$ :

where Force is the maximum applied force recorded during strain.

$$
\text { PS }=\frac{\text { Force }}{A r_{S}}
$$

Elongation at break (EB) is the ratio between the extension of the film at the point of rupture and the initial length of the sample and is expressed in percentage: 
where $a^{\prime}$ - the initial length of the film sample that is not punctured by the probe; $b$ - the penetration depth/vertical displacement by the probe; $r$ - the radius of the probe; and $a$-radius of the film in the sample holder opening.

All experiments were conducted 5 times and the mean values \pm standard deviations were calculated and evaluated statistically.

\subsection{Ex vivo mucoadhesion studies on bovine cornea}

The retention of polymeric films on bovine eyes was studied using the protocols previously reported by our group with some modifications $[35,36]$. The bovine eyes are commonly used in ocular drug delivery and irritation testing because of their availability, suitable dimensions and structural similarity to human eyes [37]. These were acquired from P.C. Turner Abattoirs (Farnborough, UK) immediately after animal slaughter and were transported to the laboratory in a cold polystyrene container. Bovine corneas were dissected within $4 \mathrm{~h}$ of eyes delivery, where the whole cornea with 2-3 mm of sclera was carefully excised using a sharp blade. Each cornea was rinsed with PBS solution, placed in Petri dishes, wrapped with cling film to reduce dehydration and stored at $4{ }^{\circ} \mathrm{C}$ to be used on the following day. Each experiment was performed in triplicate using different corneas.

Experiments were carried out with a cornea mounted on a glass slide placed on half cut falcon tubes already mounted at an angle of $45^{\circ}$ and maintained at $37{ }^{\circ} \mathrm{C}$ in an incubator. Prior to each experiment, spherically shaped polymeric discs (4 mm in diameter) containing NaFl were quickly soaked in $0.9 \% \mathrm{NaCl}$ saline solution $(1 \mathrm{sec})$ and then placed on cornea previously rinsed with $1 \mathrm{~mL}$ of simulated tear fluid (STF: $3.35 \mathrm{~g} \mathrm{NaCl}^{1} \mathrm{~g} \mathrm{NaHCO}_{3}$; and $0.0305 \mathrm{~g} \mathrm{CaCl}_{2}$ made up to $500 \mathrm{~mL}$ with deionised water). The background microscopy images were recorded for each cornea prior to administration of a fluorescent film. Then $12 \mathrm{~mL}$ of STF solution was dripped for $1 \mathrm{~h}$ on a corneal surface at a flow rate of $200 \mu \mathrm{L} / \mathrm{min}$ using a syringe pump. Fluorescence microscopy images of whole tissue were recorded after each wash every 5 min using a Leica MZ10F stereo-microscope (Leica 
Microsystems, UK) with Leica DFC3000G digital camera at $0.8 \times$ magnification and 20 ms exposure time (gain 3.0x), fitted with a GFP filter (blue, $\lambda_{\text {emission }}=512 \mathrm{~nm}$ ). The microscopy images were then analysed with ImageJ software by measuring the fluorescence pixel intensity after each washing cycle. The pixel intensity of the blank samples (corneal mucosa without a fluorescent film) was deducted from each measurement and data were normalised and converted into fluorescent intensity values using the following equation:

$$
\text { Fluorescence intensity }=\frac{I-I_{b}}{I_{0}-I_{b}} \times 100 \%
$$

where $I$ is the fluorescence intensity of a given tissue sample with a mucoadhesive film after each washing; $I_{b}$ is the background fluorescence intensity of that tissue sample (a blank sample); and $I_{0}$ is the initial fluorescence intensity of that sample (a tissue sample with mucoadhesive film on it prior to the start of first washing).

In parallel, STF solution flowing through the corneal epithelium was collected at predetermined time points and used for determination of the percentage of $\mathrm{NaFl}$ washed off the corneal surface. All the collected samples were diluted with STF, making up the total volume to $30 \mathrm{~mL}$. The amount of $\mathrm{NaFl}$ in each sample was then quantified using a FP-6200 spectrofluorometer (Jasco, UK) at $\lambda_{\text {excitation }}$ and $\lambda_{\text {emission }}$ wavelengths of 460 and $512 \mathrm{~nm}$, respectively. A standard curve used to determine the amount of $\mathrm{NaFl}$ released from the films can be found in Supplementary information (Figure S1).

All measurements were conducted in triplicate and the mean values \pm standard deviations were calculated and evaluated statistically.

\subsection{In vivo experiments}

In vivo experiments on ocular administration of fluorescent films (CHI and $\mathrm{CHI} / \mathrm{POZ})$ were conducted using chinchilla rabbits $(2.5-4.0 \mathrm{~kg})$ according to a previously described protocol [38]. These experiments were approved by Semey State Medical University (Kazakhstan) ethics committee 
and were conducted following the ARVO Statement for the Use of Animals in Ophthalmic and Visual

Research. Before the start of experiments, rabbits were housed in standard cages and allowed free access to food and water. In the beginning of each experiment rabbits were sedated with $0.2 \mathrm{~mL}$ (100 $\mathrm{mg} / \mathrm{mL}$ ) sodium thiopental (Arterium Corporation, Ukraine), previously dissolved in $10 \mathrm{~mL}$ of $0.9 \%$ $\mathrm{NaCl}$ saline solution, administered through the lateral auricular vein. Approximately 5 min after administration of sodium thiopental, polymeric discs containing $\mathrm{NaFl}$ (10 $\mathrm{mm}$ in diameter) were quickly soaked $(1 \mathrm{sec})$ in a saline solution $(0.9 \% \mathrm{NaCl})$ and carefully placed on rabbit left eye's cornea; their right eye always served as a control. The behaviour of each polymeric disc on the eye was controlled visually and images were taken at different time intervals with a high resolution digital camera. In addition, a weak UV light from an UVGL-25 Compact UV handheld lamp (Ultra-Violet Products, UK) was shone into the eye to facilitate the detection of fluorescence.

Each type of polymeric film was tested in 3 rabbits and each experiment was conducted until a film was detached or dislodged. The mean residence time values \pm standard deviations were calculated and assessed for statistical differences.

\subsection{Statistical analysis}

Data acquired during these experiments, i.e. mean values \pm standard deviations were calculated and assessed for significance using two-tailed Student's $t$-test and a one-way analysis of variance (ANOVA) followed by Bonferoni post hoc test using GraphPad Prism statistical analysis software (version 7.0; GraphPad Software Inc.), where $p<0.05$ was considered as statistically significant.

\section{RESULTS AND DISCUSSION}

\subsection{Preparation and characterisation of films}

$\mathrm{CHI}$ and $\mathrm{CHI} / \mathrm{POZ}$ blend films were successfully developed and tested. These two polymers are well characterised for their safety and biocompatibility and known to be stable under normal processing and storage conditions. POZ solutions $(0.75 \% \mathrm{w} / \mathrm{v})$ used to prepare films were easy to handle and no heating was required during their dissolution in deionised water. Chitosan solution can 
217 be obtained only via solvent casting from acidified water. All films were prepared without any 218 plasticisers and were homogenous and transparent.

The presence of amide carbonyl groups in poly(2-ethyl-2-oxazoline) suggests that this tertiary polyamide has potential for forming miscible blends with a variety of polymers containing complementary functional groups such as carboxylic, phenolic or alcoholic hydroxyl groups [39-41]. Previous studies demonstrated that carbonyl groups of POZ exhibit proton-accepting properties and participate in hydrogen bonding with proton-donating groups of other functional polymers $[40,42]$. Chitosan, in contrast to poly(2-ethyl-2-oxazoline), has in its structure numerous hydroxyl groups that can act as proton-donors with respect to the proton-accepting groups of POZ and form intermolecular hydrogen bonds. In order to establish the possibility of hydrogen bonding in chitosan/POZ blends all films were studied using FTIR spectroscopy (Figure 1). The FTIR spectrum of pure CHI film shows the presence of the broad peak appeared above $3000 \mathrm{~cm}^{-1}$ that is due to $\mathrm{OH}$ - stretching, which overlaps with NH-stretching in the same region. The peaks at $2923 \mathrm{~cm}^{-1}$ and $2889 \mathrm{~cm}^{-1}$ correspond to $\mathrm{CH}_{2}-$ and $\mathrm{CH}-$ stretching vibrations. The absorption bands at $1627 \mathrm{~cm}^{-1}$ and $1520 \mathrm{~cm}^{-1}$ are $\mathrm{C}=\mathrm{O}$ stretching (amide I) and NH-bending (amide II), respectively. The absorption band at $1416 \mathrm{~cm}^{-1}$ is attributed to $\mathrm{CH}-$ and $\mathrm{OH}-$ vibrations [10]. The band that appeared at $1377 \mathrm{~cm}^{-1}$ is assigned to the acetamide groups, which demonstrate that chitosan is not totally deacetylated and the peak at $1316 \mathrm{~cm}^{-1} \mathrm{can}$ be due to $\mathrm{C}-\mathrm{N}$ stretching (amide III) [43]. According to Bonilla et al [44] the peak at $1250 \mathrm{~cm}^{-1}$ corresponds to amino groups. The peak occurred at $1151 \mathrm{~cm}^{-1}$ is the anti-symmetric stretching of the $\mathrm{C}-\mathrm{O}-\mathrm{C}$ bridge, $1062 \mathrm{~cm}^{-1}$ and $1024 \mathrm{~cm}^{-1}$ are the skeletal vibrations involving the $\mathrm{C}-\mathrm{O}$ stretching, which are characteristics of chitosan polysaccharide structure [45].

The FTIR spectrum of POZ shows the presence of the broad absorption peak at $3488 \mathrm{~cm}^{-1}$, which is an indication of the presence of bound water that was not eliminated from the film completely. The absorption bands at $2977 \mathrm{~cm}^{-1}$ and $2939 \mathrm{~cm}^{-1}$ correspond to $\mathrm{CH}_{2}$-stretching vibrations. The characteristic bands at $1624 \mathrm{~cm}^{-1}$ and $1419 \mathrm{~cm}^{-1}$ are assigned to $\mathrm{C}=\mathrm{O}$ stretching (amide I) and $\mathrm{CH}_{3}$ bending, respectively [22]. The absorption bands at 1470,1374 and $1322 \mathrm{~cm}^{-1}(\mathrm{CH}$ 
bending) as well as 1237, 1194 and $1061 \mathrm{~cm}^{-1}$ (C-C stretching) are in good agreement with FTIR data on POZ reported in the literature [46].

All the characteristic bands of the component polymers are present in the spectra of their blends and the intensities of the bands and the shape of the peaks depend on the polymers ratio in the blend. The spectra of the miscible CHI/POZ blends show significant changes in hydroxyl stretching region, suggesting a redistribution in the arrangement of the hydroxyl group associations. When comparing the spectra corresponding to the same system as a function of composition, a shift of this band toward higher wavenumbers is observed for increasing content of POZ. This behaviour suggests that a significant part of the hydroxyl groups involved in CHI are hydrogen-bonded to amide carbonyl groups in POZ. This is in good agreement with the data reported by Fang et al [30].

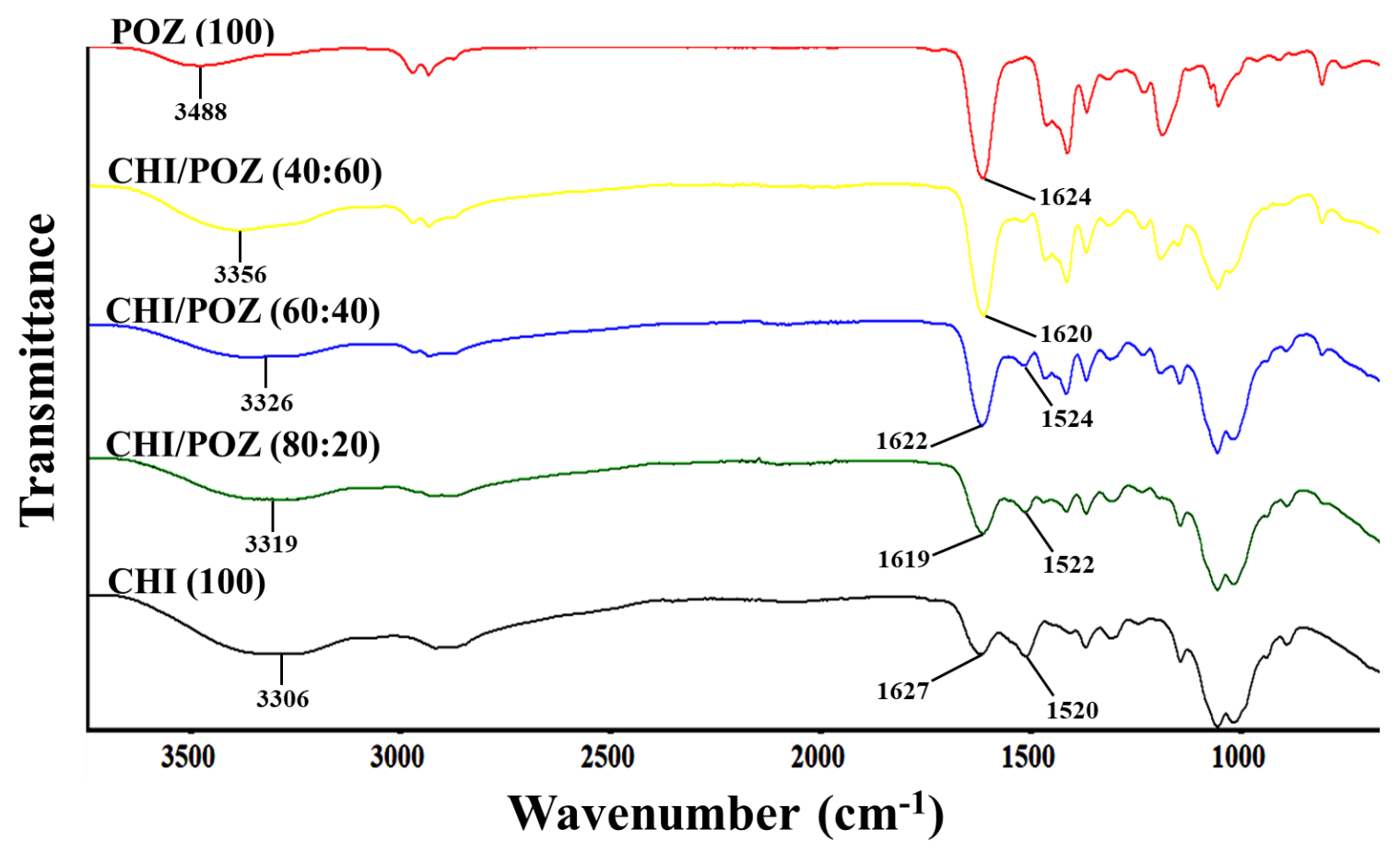

Figure 1. FTIR spectra of chitosan, POZ and CHI/POZ blends.

Thermogravimetric analysis indicates that degradation of pure chitosan film proceeds via two main stages (Figure 2): first, it starts to loose physically-bound water at $>30{ }^{\circ} \mathrm{C}$ and this process finishes at $135{ }^{\circ} \mathrm{C}$. The amount of this physically bound water in pure $\mathrm{CHI}$ film is about $13 \%$. The 
next thermal decomposition stage appears at $178-300{ }^{\circ} \mathrm{C}$ (with a maximum degradation rate observed at $188{ }^{\circ} \mathrm{C}$ ); this degradation results in $52 \%$ loss of chitosan weight. This is caused by depolymerisation of chitosan chains and pyranose rings through dehydration and deamination and finally ring-opening reaction $[47,48]$. The pure POZ film shows greater thermal stability compared to $100 \% \mathrm{CHI}$ : the first thermal event begins above $30{ }^{\circ} \mathrm{C}$, which is related to the evaporation of physically-bound water (approximately 8\%). The second stage of thermal decomposition of POZ starts above $315^{\circ} \mathrm{C}$ (with the maximal degradation rate observed at $395{ }^{\circ} \mathrm{C}$ ) reaching $92 \%$ of the total weight loss at $430{ }^{\circ} \mathrm{C}$. A single decomposition stage of dry POZ at $400{ }^{\circ} \mathrm{C}$ was previously reported by Beruhil Adatoz et al [49], which broadly agrees with our data. The decomposition profiles of $\mathrm{CHI} / \mathrm{POZ}$ blends are characterised by three stages: (1) $25-150{ }^{\circ} \mathrm{C}$, corresponding to the loss of physically bound water, (2) $175-275^{\circ} \mathrm{C}$, corresponding to the degradation of CHI, and (3) $275-$ $425^{\circ} \mathrm{C}$, corresponding to the degradation of POZ. It should be noted that the temperatures, at which the degradation rates of stages (2) and (3) were maximal, showed a good correlation with the composition of the blends (Figure S2, Supplementary information). This indicates that the presence of more thermally stable POZ in the blend improves the thermal stability of less stable chitosan, which may be due to the presence of weak hydrogen bonding between these polymers.

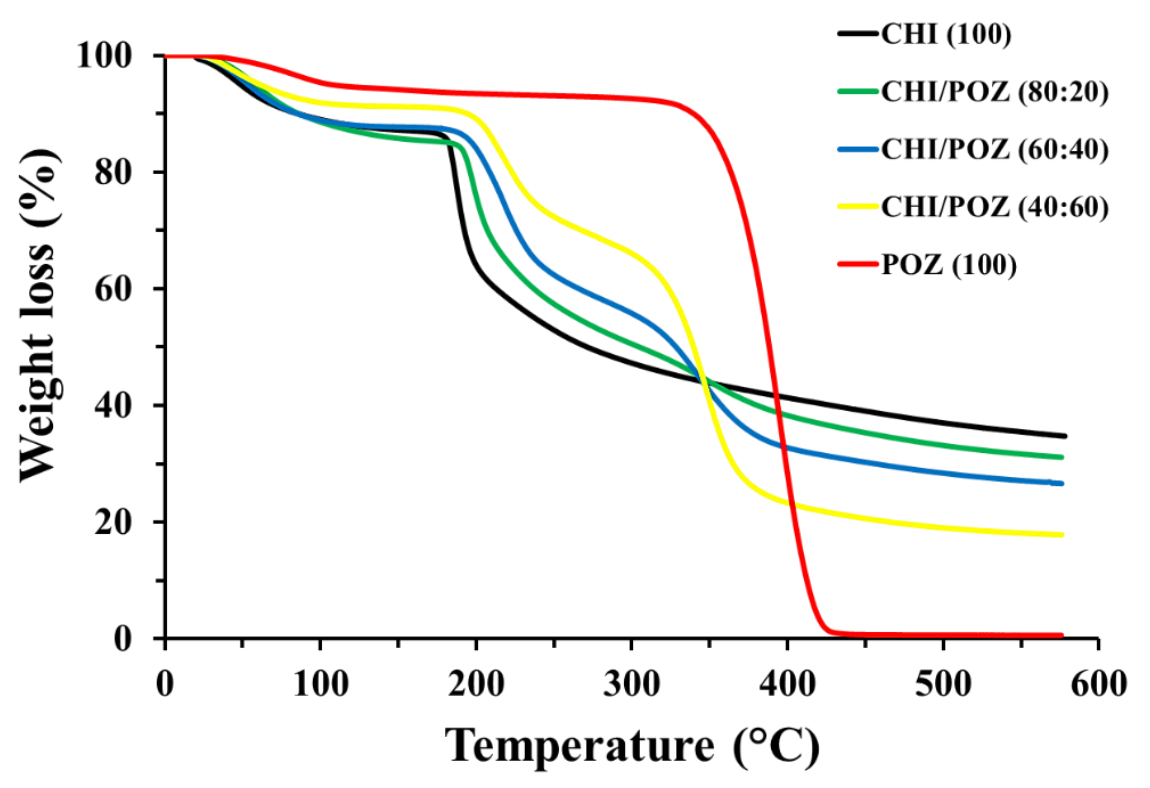

Figure 2. TGA curves of pure $\mathrm{CHI}$, pure $\mathrm{POZ}$ and $\mathrm{CHI} / \mathrm{POZ}$ blend films. 
Differential scanning calorimetry (DSC) was used to characterize the miscibility between the 277 polymers. Usually the presence of a single glass transition temperature, situated between Tg values 278 of individual polymer components indicates a complete miscibility. Figure 3 shows that the presence 279 of a single glass transition in the blends, which depends on the composition of the polymer mixture. All glass transition temperatures of the blends are between the $\mathrm{Tg}$ values of individual $\mathrm{POZ}\left(56{ }^{\circ} \mathrm{C}\right)$ and chitosan $\left(131^{\circ} \mathrm{C}\right)$, which is in good agreement with the data reported by Fang et al [30].

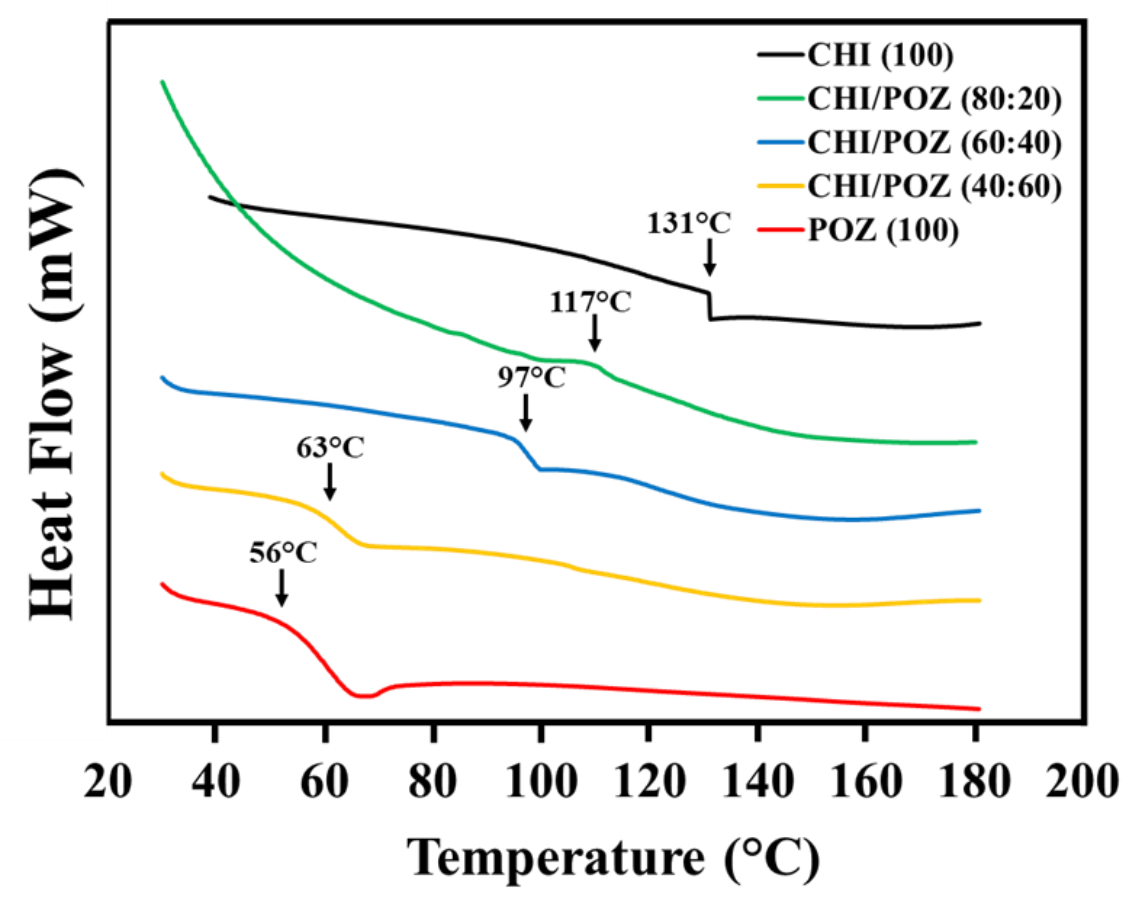

Figure 3. DSC thermograms of pure CHI, pure POZ and CHI/POZ blend films. polymers (Figure 4). WAXD diffractograms of pure CHI and POZ films show a broad halo typical for predominantly amorphous polymers. Pure CHI still shows the presence of four diffraction peaks at $2 \theta=8.5^{\circ} ; 11.8^{\circ} ; 18.1^{\circ}$ and $23.8^{\circ}$, which is typical for crystalline domains in this polysaccharide and is consistent with our previous report [50]. The diffractogram of pure POZ film shows the presence of two broad amorphous humps centred at $2 \theta=10.4^{\circ}$ and $18.8^{\circ}$, indicating non-crystalline nature of this polymer, which is also consistent with the literature data $[51,52]$. 
Diffraction peaks characteristic of chitosan are also present in the blend film, however a shift 292 of a broad diffraction peak from $23.3^{\circ}$ to $19.2^{\circ}$ is observed. This may indicate that chitosan is involved 293 in some weak interaction with POZ that affects the formation and structure of its crystalline domains.

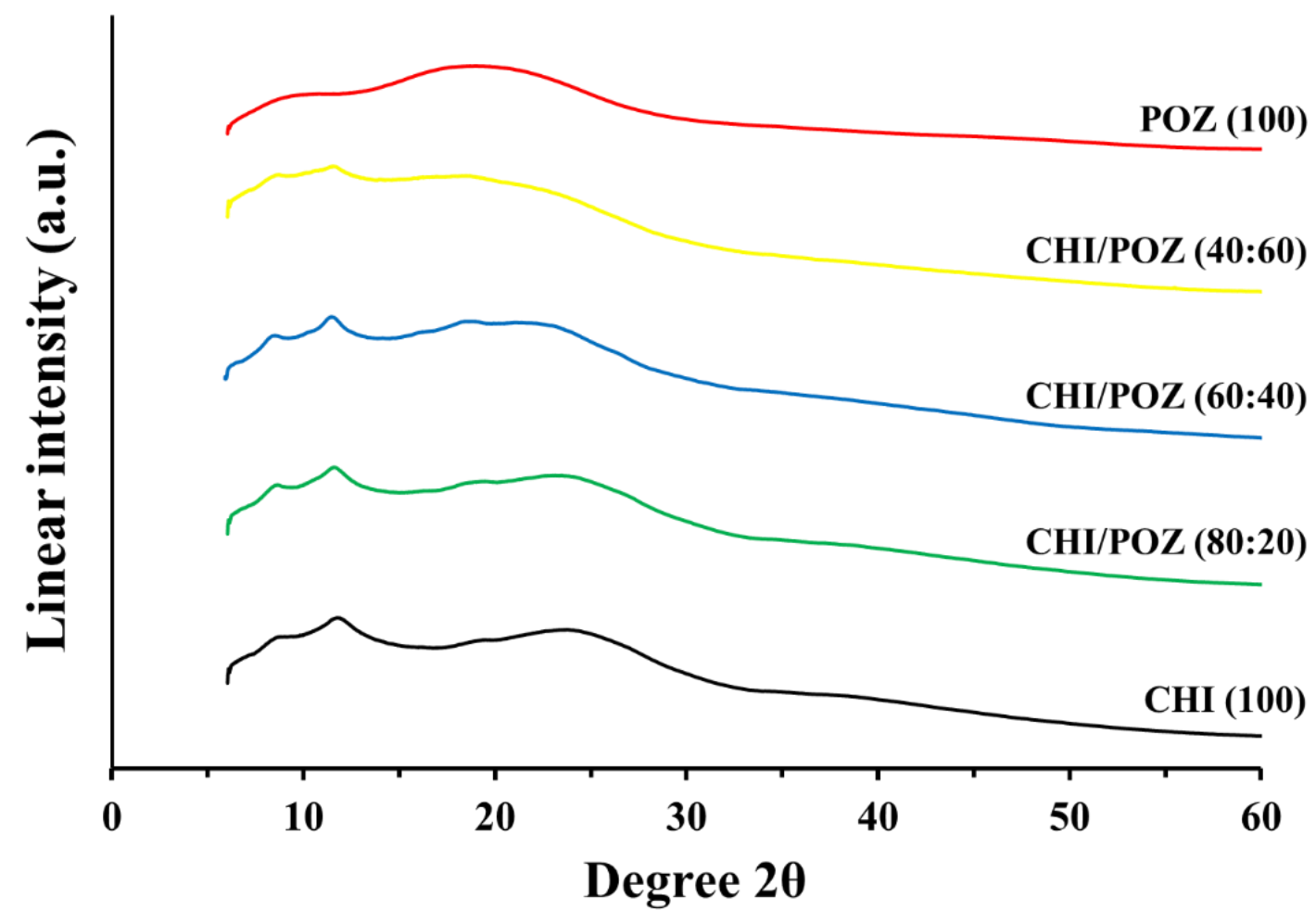

295 Figure. 4. WAXD diffractograms of $\mathrm{CHI}$ and $\mathrm{CHI} / \mathrm{POZ}$ blend films.

The morphology of the polymer film cross-sections and surface were studied by scanning 297 electron microscope (SEM). The investigation of the sample cross-sections at high magnification 298 (2000x) reveals that the films have fully homogeneous structure with no signs of phase separation 299 and interface boundaries (Figure 5). Thus, the SEM data provides another evidence for miscibility 300 between $\mathrm{CHI}$ and POZ in the solid state at different ratios. 


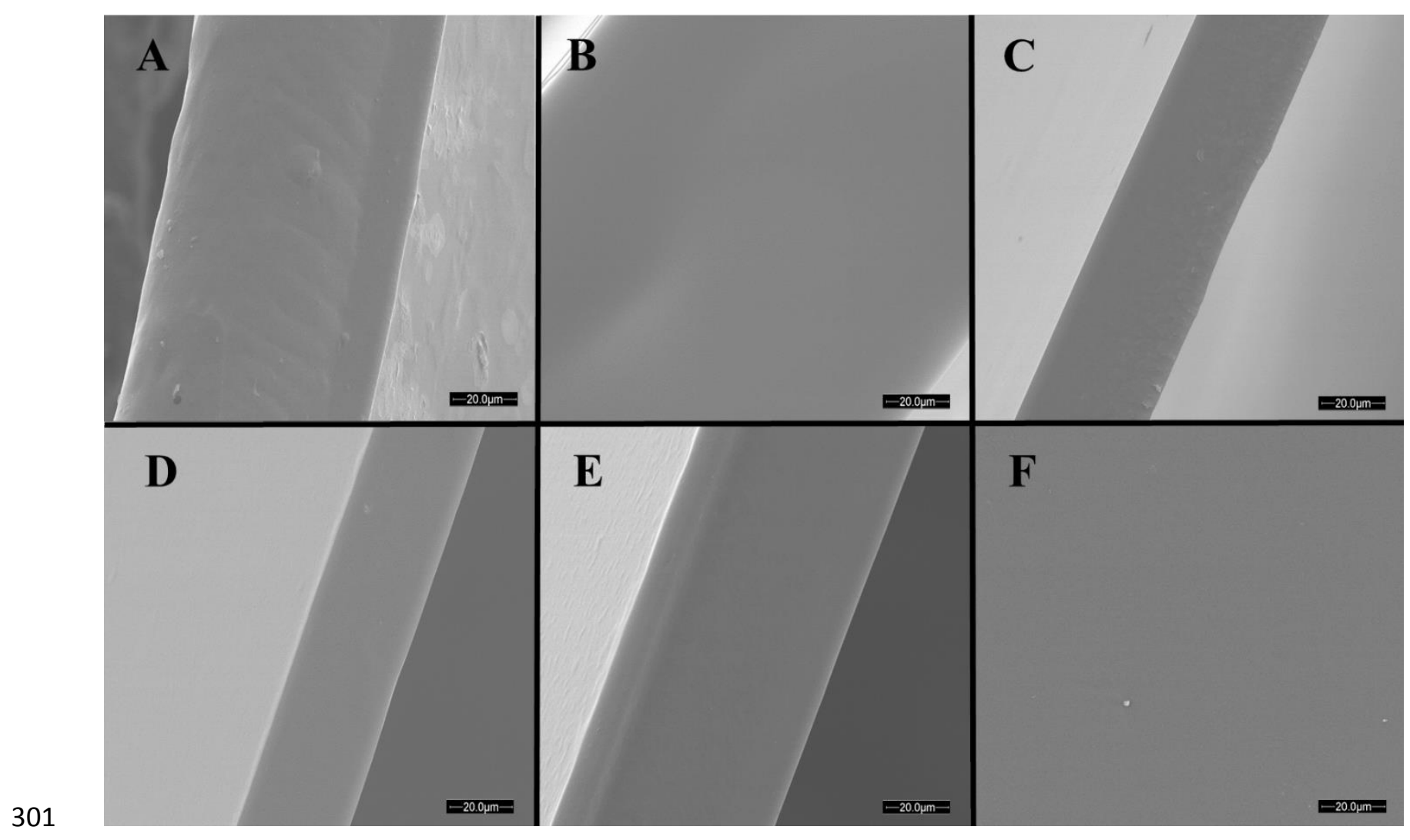

302 Figure 5. SEM images of (A) CHI, (B) pure POZ, and their blend (C, D, E) cross- sections and (F) 303 surface. Content of POZ in the blends: 20 (C), 40 (D) and $60 \%$ (E, F). Scale bars are $20 \mu \mathrm{m}$.

The films composed of the blends with different $\mathrm{CHI}$ and POZ ratios were examined by 305 elongation and puncture strength analysis and the results are shown in Figure 6. A film composed of 306 pure POZ was not suitable for this type of analysis because of its extreme brittleness. Comparing the 307 mechanical properties of pure $\mathrm{CHI}$ films with the polymer blends indicates that an increase in POZ 308 content in the sample results in gradual reduction in the elongation at break and puncture strength 309 values. 

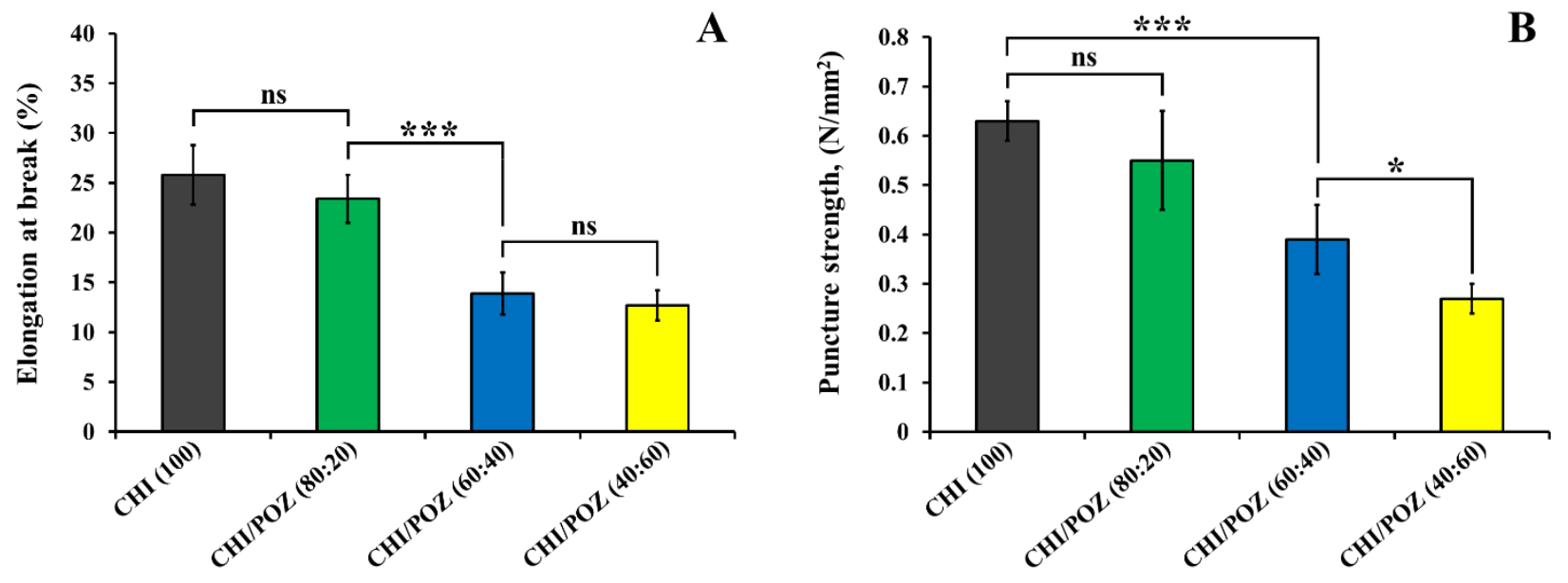

Figure 6. Mechanical analysis of $\mathrm{CHI}$ and $\mathrm{CHI} / \mathrm{POZ}$ blend films: elongation at break (A) and puncture strength (B). Data are expressed as mean \pm standard deviation $(n=5)$. Statistically significant differences are given as: $* * *-p<0.001 ; *-p<0.05$; ns - no significance.

\subsection{Mucosal retention of blend films on ex vivo corneal tissue}

Soluble or swellable polymeric films have been used in ocular therapeutics either to improve the efficiency of drug delivery (compared to conventional eye drops), or to protect the injured cornea [53-55]. These films should exhibit some mucoadhesive properties to have a prolonged residence on the mucosa; however, eventually these materials are supposed to dissolve in the tear fluid completely or should allow their non-traumatising detachment from the ocular surface. These dosage forms should have excellent mechanical properties and a balanced mucoadhesiveness. Materials with insufficiently mucoadhesive properties will not be suitable because of the difficulties in their attachment to the ocular surface and, on the contrary, excessively films will cause discomfort because they may interfere with blinking [56]. Chitosan has previously been reported as a potential material for preparation of mucoadhesive ocular films [57-60]. It exhibits superior mucoadhesive properties compared to many other pharmaceutical polymers, which often needs to be moderated to make it suitable for a particular application. In the present work we have evaluated the suitability of CHI/POZ blends as materials for application as mucoadhesive ocular films.

Fluorescein sodium $(\mathrm{NaFl})$ was used as a model drug to demonstrate the potential use of 
CHI/POZ films for the application in ocular drug delivery. The retention of CHI and CHI/POZ films containing $0.1 \% \mathrm{NaFl}$ on freshly isolated bovine cornea was assessed using a flow-through in vitro technique with fluorescent detection. This methodology has been previously used to study the retention of various materials on different mucosal surfaces, including ocular tissues, and it was validated against the other techniques established in assessment of mucoadhesive properties $[35,36,38,61,62]$. Figure 7 illustrates exemplary fluorescent images of the retention of polymeric films on bovine corneal mucosa irrigated with STF $(200 \mu \mathrm{L} / \mathrm{min})$. The fluorescence intensity on the mucosa was monitored following each washing cycle over $60 \mathrm{~min}$. After analysing the fluorescent images using ImageJ software, it can be seen that CHI and CHI/POZ films showed an initial increase in fluorescence intensity after the first wash (Figure 8). This can potentially be related to the moisture effect on fluorescent films, causing an increased brightness that leads to $>100 \%$ fluorescence intensity values. Despite of this initial increase in the fluorescence intensity, the subsequent washes resulted in the reduction of fluorescence intensity due to the dissolution of the films and subsequent wash out of $\mathrm{NaFl}$. It was established that 100\% CHI and CHI/POZ (80:20 and 60:40) exhibited significantly greater retention $(p<0.01)$ in the initial washing cycles (except for $\mathrm{CHI}$ after 60 min washing, 12 mL STF, $p<0.05)$ compared to CHI/POZ (40:60). It could be concluded that introduction of POZ made the films less retentive. This observation is consistent with our previous studies reporting that decorating nanoparticles with POZ makes them less mucoadhesive [22-24]. Moreover, the retention of CHI/POZ films (80:20 and 60:40) on ocular mucosa was found not to be significantly different from CHI $(p>0.05)$ demonstrating a similar retention profile until the end of washing cycles (Figure 8).

In parallel, STF solution flowing down the corneal surface during each washing cycle was collected at pre-determined time intervals and analysed using fluorescent spectrometry. An insert in Figure 8 depicts the cumulative percentage release of fluorescein sodium from $\mathrm{CHI}$ and $\mathrm{CHI} / \mathrm{POZ}$ films. It was revealed that $\mathrm{CHI} / \mathrm{POZ}$ (40:60) films released the highest amount of NaFl after total washing cycle over 60 min compared to $100 \% \mathrm{CHI}$ and $\mathrm{CHI} / \mathrm{POZ}$ (80:20 and 60:40). In the course 
of work, the use of $\mathrm{NaFl}$ with the concentration higher than $0.1 \mathrm{mg} / \mathrm{mL}$ led to the formation of strong complexes with chitosan and precipitation of complexes were observed. Fluorescein sodium is a negatively charged compound and therefore may form complexes with the positively charged backbones of chitosan due to the electrostatic attraction forces. Hence, $\mathrm{NaFl}$ with lower concentration was used to prepare fluorescent films based on different ratios of $\mathrm{CHI}$ and POZ. Considering the composition of $\mathrm{CHI} / \mathrm{POZ}$ fluorescent films, therefore, the lower content of chitosan in the blend film, the more $\mathrm{NaFl}$ is released. The fact that $100 \% \mathrm{CHI}$ released less $\mathrm{NaFl}$ could be explained by partial entrapment of fluorescein sodium within the corneal epithelium, or/and by mucoadhesive effects of chitosan, i.e. specific interactions of chitosan macromolecules with the ocular surface.
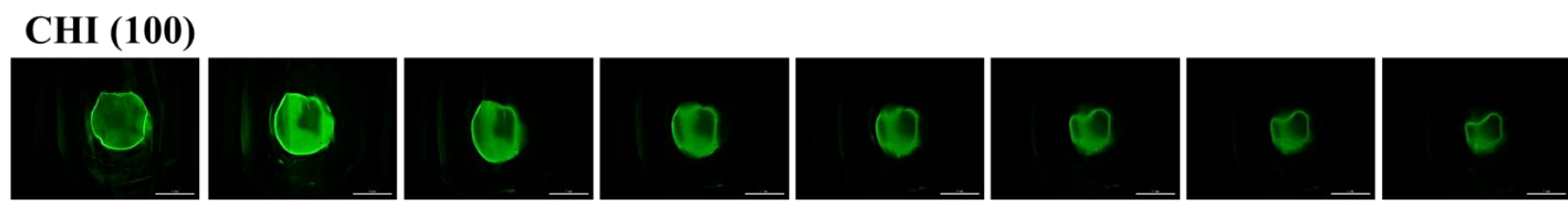

\section{CHI/POZ (80:20)}
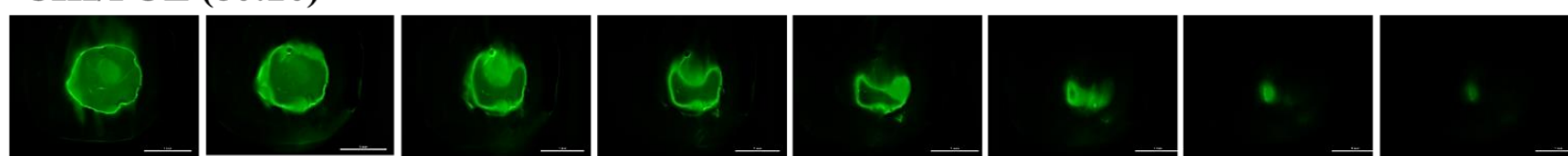

\section{CHI/POZ (60:40)}
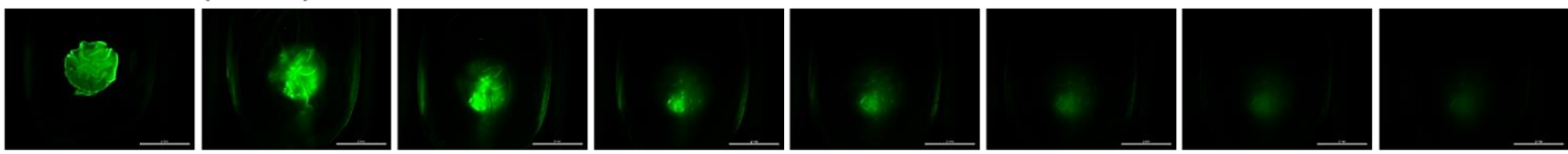

CHI/POZ (40:60)

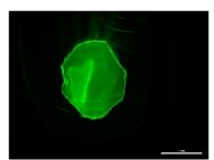

0

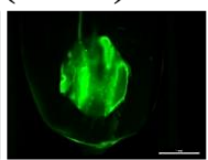

5

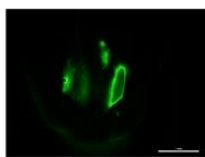

10

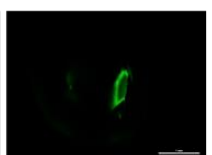

20

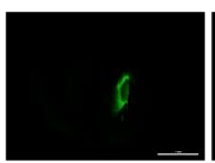

30

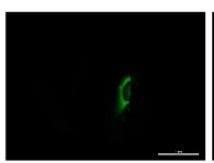

40

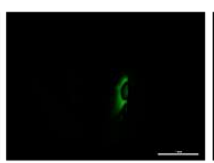

50

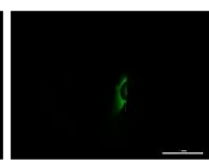

$60 \mathrm{~min}$

Figure 7. Exemplary fluorescent microphotographs showing mucosal retention of $\mathrm{CHI}$ and $\mathrm{CHI} / \mathrm{POZ}$

films on freshly excised bovine cornea washed with different volumes of STF ( $200 \mu \mathrm{L} / \mathrm{min})$ over 60 min. Scale bars are $1 \mu \mathrm{m}$. 
$\square C H I(100) \quad \square C H I / P O Z(80: 20) \quad \square C H I / P O Z(60: 40) \quad \square C H I / P O Z(40: 60)$

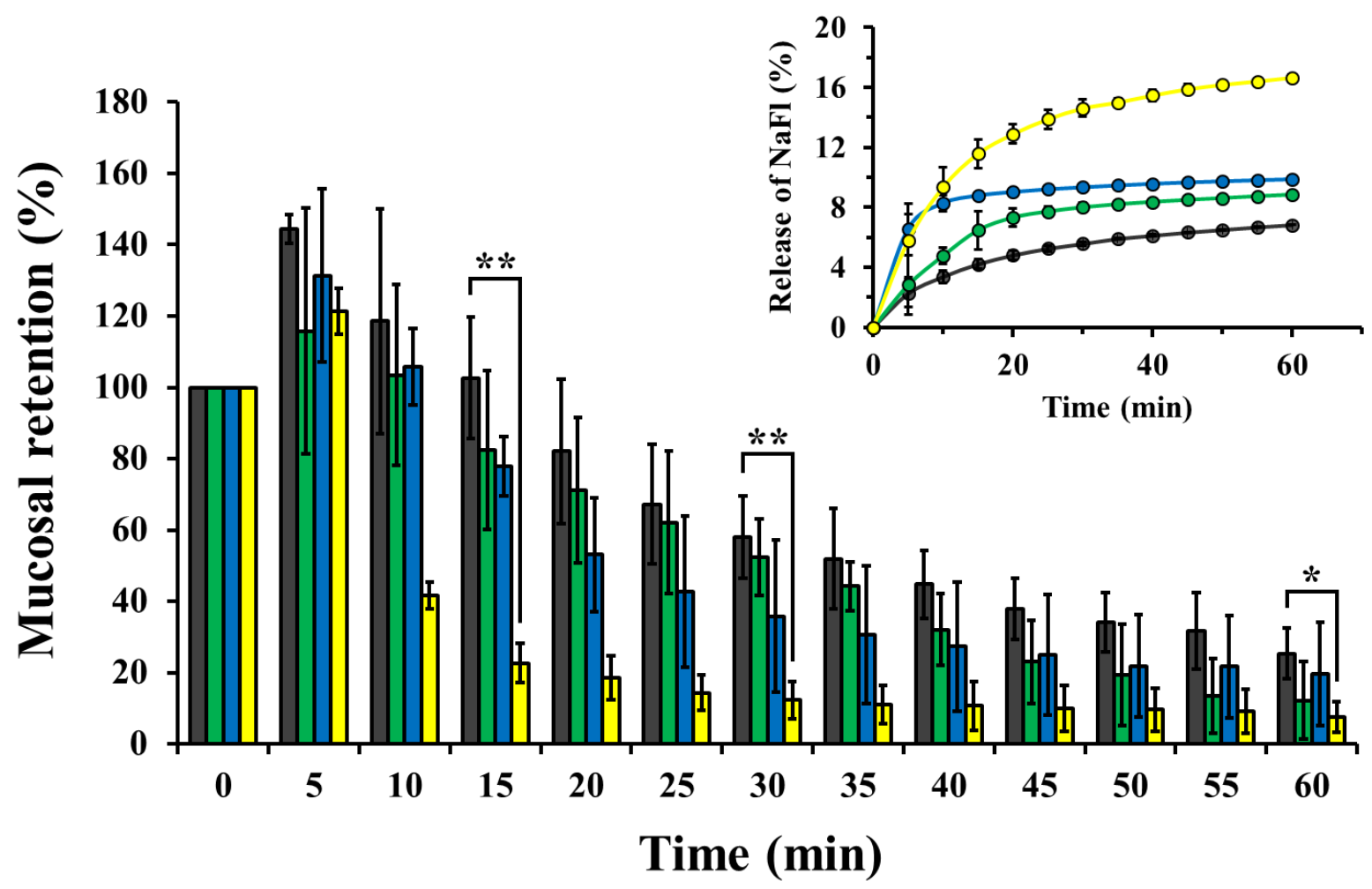

Figure 8. Mucosal retention of $\mathrm{CHI}$ and $\mathrm{CHI} / \mathrm{POZ}$ films on fresh bovine cornea after irrigating with different volumes of STF $(200 \mu \mathrm{L} / \mathrm{min})$ over $60 \mathrm{~min}$. All values are the means \pm standard deviations of triplicate experiments. Statistically significant differences are given as: $*^{*}-p<0.01 ; *_{-} p<0.05$.

\subsection{In vivo retention studies}

Taking into consideration the known non-toxic and non-irritant nature of both chitosan and POZ $[14,63]$ the mucoadhesive films were tested directly in vivo without prior evaluation of their biocompatibility in cell culture or other in vitro irritation models.

In vivo experiments were carried out in rabbits $(\mathrm{n}=3)$ with round-shaped $10 \mathrm{~mm} \mathrm{CHI}$ and $\mathrm{CHI} / \mathrm{POZ}$ films containing $0.1 \mathrm{mg} / \mathrm{mL} \mathrm{NaFl}$. Each formulation was placed on corneal mucosa of a chinchilla rabbit's left eye and their retention was monitored visually by taking photographs at regular time points until the films detached. A UV lamp was used to enhance the detection of fluorescence.

Figure 9 shows exemplary images of rabbit eyes with fluorescent films administered in vivo providing even coverage of the cornea and subsequent changes were observed, i.e. time of 
detachment, physical changes such as films swelling and wrinkling. The results for all other formulations are presented in Figures S3-S6 (Supplementary information). Films made of 100\% POZ were not suitable for in vivo experiments due to their extreme brittleness. The in vivo results indicate that pure $\mathrm{CHI}$ and $\mathrm{CHI} / \mathrm{POZ}$ films could achieve from at least $10 \mathrm{~min}$ to up to $50 \mathrm{~min}$ residence on the ocular surface, which is consistent with in vitro data. Generally, all the films exhibited excellent adhesion to the cornea. However, the presence of a nictitating membrane on chinchilla rabbit cornea often led to the dislodging or a complete removal of the films from the corneal surface into the lower fornix of conjunctiva. This greatly affected in vivo data reproducibility. No significant differences $(p$ $>0.05$ ) were observed between all film formulations in terms of their retention on the rabbit's cornea (Figure 10). It is expected that these films will exhibit much better retention in human tests because these dosage forms will not be voluntarily dislodged or removed. It should also be noted that the films did not cause any observable discomfort, irritation, inflammatory reactions or excessive tear production in rabbit eyes, which indicate that these materials are biocompatible and potentially suitable for ocular administration.

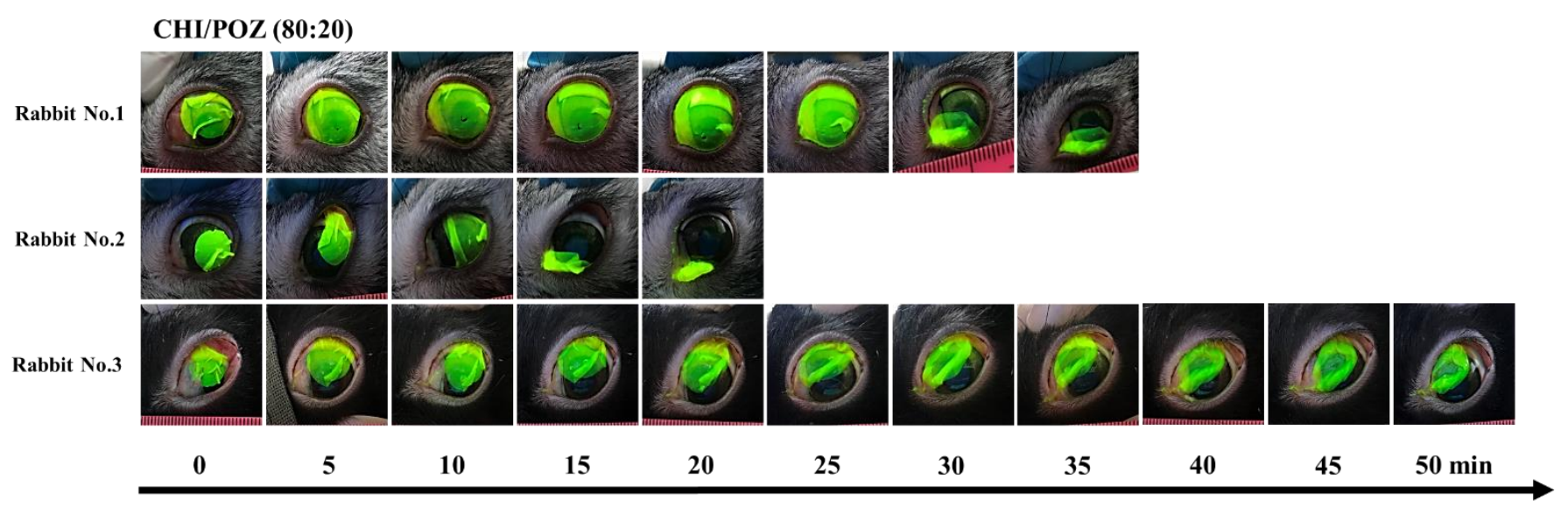

Figure 9. Exemplary photographs of in vivo mucosal retention of CHI/POZ (80:20) films on rabbit eyes taken at different time intervals. 
399

400

401

402

403

404

405

406

407

408

409

410

411

412 for ocular drug delivery both in vitro and in vivo. The results indicate that these films are 413 biocompatible and do not cause any irritation to the eye. They also exhibit ability to adhere to the 414 cornea and to retain for up to $50 \mathrm{~min}$, providing a sustained drug release.

Figure 10. In vivo mucosal retention of $\mathrm{CHI}$ and $\mathrm{CHI} / \mathrm{POZ}$ blend films on rabbit eye. Data are expressed as mean \pm standard deviation $(n=3)$.

\section{CONCLUSIONS}

Polymeric blends of chitosan and poly(2-ethyl-2-oxazoline) were prepared in the form of flexible and transparent films using casting from aqueous solutions with subsequent solvent evaporation. The structure and physicochemical properties of these films were evaluated using Fourier-transformed infrared spectroscopy, thermal gravimetric analysis, differential scanning calorimetry, wide angle x-ray diffraction, tensile testing and scanning electron microscopy. These studies indicated a complete miscibility between the polymers in the blends. Blending of chitosan and poly(2-ethyl-2-oxazoline) leads to a significant reduction of the films mechanical properties (elongation at break and puncture strength). The films based on pure chitosan and blends with poly(2ethyl-2-oxazoline) were formulated with sodium fluorescein and evaluated as potential dosage forms

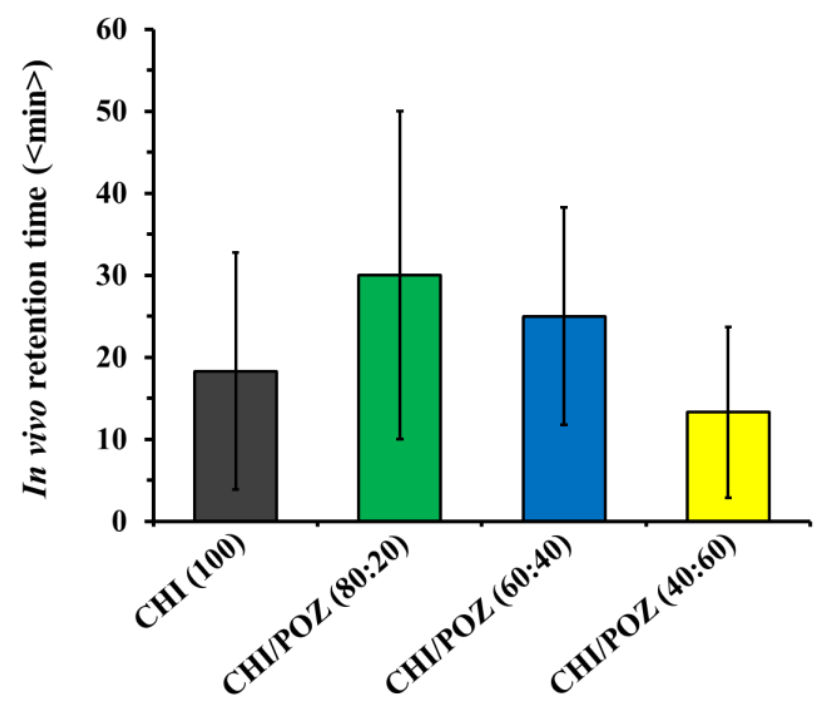




\section{ACKNOWLEDGEMENTS}

Chemical Analysis Facility (University of Reading) is thanked for providing access to DSC, SEM, TGA and PXRD instruments. The authors are grateful to Amanpreet Kaur and Nick Spencer (University of Reading) for their help with scanning electron microscopy and X-ray diffraction experiments, respectively. G.K.A. acknowledges Ministry of Education and Science of the Republic of Kazakhstan for the research grant (No. AP05133221). D.B.K. gratefully acknowledges the British Council Newton-Al-Farabi Partnership Programme, the Researcher Links Post-Doctoral Mobility Grant (No. 216046068) for financial support of his 2-years of postdoctoral fellowship at the University of Reading. P.C. Turner Abattoirs (Farnborough, United Kingdom) is also thanked for providing bovine eye tissues for experiments. The authors are grateful to Shariat Bolatova (Semey State Medical University, Kazakhstan) for her technical assistance with in vivo experiments.

\section{DATA AVAILABILITY AND SUPPLEMENTARY INFORMATION}

The Supplementary Information is available free of charge in PDF format. It contains a standard curve used to determine the amount of freed fluorescein sodium from CHI and CHI/POZ films (Figure S1); correlation between the maximal decomposition rate temperature and composition of polymer blends (Figure S2); and exemplary photographs of in vivo mucosal retention of CHI and CHI/POZ films on rabbit eyes taken at different time points (Figure S3-S6).

\section{ABBREVIATIONS}

CHI, chitosan; DSC, differential scanning calorimetry; EB, elongation at break; PBS, phosphate buffered saline; POZ, poly(2-ethyl-2-oxazoline); PS, puncture strength; SEM, scanning electron microscope; STF, simulated tear fluid; NaFl, fluorescein sodium salt; TGA, thermogravimetric analysis; WAXD, wide-angle X-Ray diffraction. 


\section{Author contributions}

The manuscript was written through contributions of all authors. All authors have given approval to the final version of the manuscript.

\section{Notes}

The authors declare no competing financial interest.

\section{ORCID ID of authors}

Daulet B. Kaldybekov: https://orcid.org/0000-0002-7191-5465

Aisulu Zh. Saimova: $\underline{\text { https://orcid.org/0000-0002-9564-732X }}$

Galiya S. Irmukhametova: https://orcid.org/0000-0002-1264-7974

Vitaliy V. Khutoryanskiy: https://orcid.org/0000-0002-7221-2630

\section{REFERENCES}

[1] G.P. Andrews, T.P. Laverty, D.S. Jones, Mucoadhesive polymeric platforms for controlled drug delivery, Eur. J. Pharm. Biopharm. 71 (2009) 505-518. doi:https://doi.org/10.1016/j.ejpb.2008.09.028.

[2] V. V. Khutoryanskiy, Advances in mucoadhesion and mucoadhesive polymers, Macromol. Biosci. 11 (2011) 748-764. doi:10.1002/mabi.201000388.

[3] V. V. Khutoryanskiy, Mucoadhesive Materials and Drug Delivery Systems, John Wiley \& Sons, Ltd, Chichester, UK, 2014. doi:10.1002/9781118794203.

[4] S. Mansuri, P. Kesharwani, K. Jain, R.K. Tekade, N.K. Jain, Mucoadhesion: A promising approach in drug delivery system, React. Funct. Polym. 100 (2016) 151-172. doi:https://doi.org/10.1016/j.reactfunctpolym.2016.01.011.

[5] A.R. Mackie, F.M. Goycoolea, B. Menchicchi, C.M. Caramella, F. Saporito, S. Lee, K. Stephansen, I.S. Chronakis, M. Hiorth, M. Adamczak, M. Waldner, H. Mørck Nielsen, L. 
Marcelloni, Innovative methods and applications in mucoadhesion research, Macromol. Biosci. 17 (2017) 1600534. doi:10.1002/mabi.201600534.

[6] M. Amidi, E. Mastrobattista, W. Jiskoot, W.E. Hennink, Chitosan-based delivery systems for protein therapeutics and antigens, Adv. Drug Deliv. Rev. 62 (2010) 59-82. doi:https://doi.org/10.1016/j.addr.2009.11.009.

[7] A. Bernkop-Schnürch, S. Dünnhaupt, Chitosan-based drug delivery systems, Eur. J. Pharm. Biopharm. 81 (2012) 463-469. doi:https://doi.org/10.1016/j.ejpb.2012.04.007.

[8] L. Casettari, L. Illum, Chitosan in nasal delivery systems for therapeutic drugs, J. Control. Release. 190 (2014) 189-200. doi:https://doi.org/10.1016/j.jconrel.2014.05.003.

[9] T.M.M. Ways, W.M. Lau, V. V Khutoryanskiy, Chitosan and its derivatives for application in mucoadhesive drug delivery systems, Polymers (Basel). 10 (2018) 267-304. doi:10.3390/polym10030267.

[10] K. Luo, J. Yin, O. V Khutoryanskaya, V. V Khutoryanskiy, Mucoadhesive and elastic films based on blends of chitosan and hydroxyethylcellulose, Macromol. Biosci. 8 (2008) 184192. doi:10.1002/mabi.200700185.

[11] M.S. Freag, W.M. Saleh, O.Y. Abdallah, Exploiting polymer blending approach for fabrication of buccal chitosan-based composite sponges with augmented mucoadhesive characteristics, Eur. J. Pharm. Sci. 120 (2018) 10-19. doi:https://doi.org/10.1016/j.ejps.2018.04.041.

[12] R.H. Sizílio, J.G. Galvão, G.G.G. Trindade, L.T.S. Pina, L.N. Andrade, J.K.M.C. Gonsalves, A.A.M. Lira, M. V Chaud, T.F.R. Alves, M.L.P.M. Arguelho, R.S. Nunes, Chitosan/PVPbased mucoadhesive membranes as a promising delivery system of betamethasone-17valerate for aphthous stomatitis, Carbohydr. Polym. 190 (2018) 339-345. doi:https://doi.org/10.1016/j.carbpol.2018.02.079.

[13] R. Hoogenboom, Poly(2-oxazoline)s: A polymer class with numerous potential applications, Angew. Chemie Int. Ed. 48 (2009) 7978-7994. doi:10.1002/anie.200901607. 
[14] R. Luxenhofer, Y. Han, A. Schulz, J. Tong, Z. He, A. V Kabanov, R. Jordan, Poly(2oxazoline)s as polymer therapeutics, Macromol. Rapid Commun. 33 (2012) 1613-1631. doi:10.1002/marc.201200354.

[15] O. Sedlacek, B.D. Monnery, S.K. Filippov, R. Hoogenboom, M. Hruby, Poly(2-Oxazoline)s - Are they more advantageous for biomedical applications than other polymers?, Macromol. Rapid Commun. 33 (2012) 1648-1662. doi:10.1002/marc.201200453.

[16] H. Bludau, A.E. Czapar, A.S. Pitek, S. Shukla, R. Jordan, N.F. Steinmetz, POxylation as an alternative stealth coating for biomedical applications, Eur. Polym. J. 88 (2017) 679-688. doi:https://doi.org/10.1016/j.eurpolymj.2016.10.041.

[17] T. Lorson, M.M. Lübtow, E. Wegener, M.S. Haider, S. Borova, D. Nahm, R. Jordan, M. Sokolski-Papkov, A. V Kabanov, R. Luxenhofer, Poly(2-oxazoline)s based biomaterials: A comprehensive and critical update, Biomaterials. 178 (2018) 204-280. doi:https://doi.org/10.1016/j.biomaterials.2018.05.022.

[18] A. Sundaramurthy, M. Vergaelen, S. Maji, R. Auzély-Velty, Z. Zhang, B.G. De Geest, R. Hoogenboom, Hydrogen bonded multilayer films based on poly(2-oxazoline)s and tannic acid, Adv. Healthc. Mater. 3 (2014) 2040-2047. doi:10.1002/adhm.201400377.

[19] S. Hendessi, P.T. Güner, A. Miko, A.L. Demirel, Hydrogen bonded multilayers of poly(2ethyl-2-oxazoline) stabilized silver nanoparticles and tannic acid, Eur. Polym. J. 88 (2017) 666-678. doi:https://doi.org/10.1016/j.eurpolymj.2016.10.039.

[20] C. Su, J. Sun, X. Zhang, D. Shen, S. Yang, Hydrogen-bonded polymer complex thin film of poly(2-oxazoline) and poly(acrylic acid), Polymers (Basel). 9 (2017) 363. doi:10.3390/polym9080363.

[21] R. Hoogenboom, H. Schlaad, Thermoresponsive poly(2-oxazoline)s, polypeptoids, and polypeptides, Polym. Chem. 8 (2017) 24-40. doi:10.1039/C6PY01320A.

[22] E.D.H. Mansfield, K. Sillence, P. Hole, A.C. Williams, V. V Khutoryanskiy, POZylation: a new approach to enhance nanoparticle diffusion through mucosal barriers, Nanoscale. 7 

(2015) 13671-13679. doi:10.1039/C5NR03178H.

[23] E.D.H. Mansfield, V.R. de la Rosa, R.M. Kowalczyk, I. Grillo, R. Hoogenboom, K. Sillence, P. Hole, A.C. Williams, V. V Khutoryanskiy, Side chain variations radically alter the diffusion of poly(2-alkyl-2-oxazoline) functionalised nanoparticles through a mucosal barrier, Biomater. Sci. 4 (2016) 1318-1327. doi:10.1039/C6BM00375C.

[24] T.M.M. Ways, W.M. Lau, K.W. Ng, V. V Khutoryanskiy, Synthesis of thiolated, PEGylated and POZylated silica nanoparticles and evaluation of their retention on rat intestinal mucosa in vitro, Eur. J. Pharm. Sci. 122 (2018) 230-238. doi:https://doi.org/10.1016/j.ejps.2018.06.032.

[25] L. Ruiz-Rubio, M.L. Alonso, L. Pérez-Álvarez, R.M. Alonso, J.L. Vilas, V. V Khutoryanskiy, Formulation of Carbopol®/Poly(2-ethyl-2-oxazoline)s mucoadhesive tablets for buccal delivery of hydrocortisone, Polymers (Basel). 10 (2018) 175. doi:10.3390/polym10020175.

[26] J. Dai, S.H. Goh, S.Y. Lee, K.S. Slow, Complexation between poly(2-hydroxypropyl methacrylate) and three tertiary amide polymers, J. Appl. Polym. Sci. 53 (1994) 837-845. doi:10.1002/app.1994.070530701.

[27] J. Dai, S.H. Goh, S.Y. Lee, K.S. Siow, Miscibility and interpolymer complexation of poly(2methyl-2-oxazoline) with hydroxyl-containing polymers, J. Polym. Res. 2 (1995) 209-215. doi:10.1007/BF01492772.

[28] J.R. Isasi, E. Meaurio, C. Cesteros, I. Katime, Miscibility and specific interactions in blends of poly(2-ethyl-2-oxazoline) with hydroxylated polymethacrylates, Macromol. Chem. Phys. 197 (1996) 641-649. doi:10.1002/macp.1996.021970219.

[29] S. Kobayashi, M. Kaku, T. Saegusa, Miscibility of poly(2-oxazolines) with commodity polymers, Macromolecules. 21 (1988) 334-338. doi:10.1021/ma00180a009.

[30] L. Fang, S.H. Goh, Miscible chitosan/tertiary amide polymer blends, J. Appl. Polym. Sci. 76 (2000) 1785-1790. doi:10.1002/(SICI)1097-4628(20000620)76:12<1785::AID- 
APP8>3.0.CO;2-B.

[31] P.J.A. Sobral, F.C. Menegalli, M.D. Hubinger, M.A. Roques, Mechanical, water vapor barrier and thermal properties of gelatin based edible films, Food Hydrocoll. 15 (2001) 423432. doi:10.1016/S0268-005X(01)00061-3.

[32] S. Mali, M.V.E. Grossmann, M.A. García, M.N. Martino, N.E. Zaritzky, Barrier, mechanical and optical properties of plasticized yam starch films, Carbohydr. Polym. 56 (2004) 129_ 135. doi:10.1016/j.carbpol.2004.01.004.

[33] M. Preis, K. Knop, J. Breitkreutz, Mechanical strength test for orodispersible and buccal films, Int. J. Pharm. 461 (2014) 22-29. doi:10.1016/J.IJPHARM.2013.11.033.

[34] R. Gnanasambandam, N.S. Hettiarachchy, M. Coleman, Mechanical and barrier properties of rice bran films, J. Food Sci. 62 (1997) 395-398. doi:10.1111/j.1365-2621.1997.tb04009.x.

[35] G.S. Irmukhametova, G.A. Mun, V. V Khutoryanskiy, Thiolated mucoadhesive and PEGylated nonmucoadhesive organosilica nanoparticles from 3mercaptopropyltrimethoxysilane, Langmuir. 27 (2011) 9551-9556. doi:10.1021/la201385h.

[36] E.A. Mun, P.W.J. Morrison, A.C. Williams, V. V Khutoryanskiy, On the barrier properties of the cornea: A microscopy study of the penetration of fluorescently labeled nanoparticles, polymers, and sodium fluorescein, Mol. Pharm. 11 (2014) 3556-3564. doi:10.1021/mp500332m.

[37] P.W.J. Morrison, N.N. Porfiryeva, S. Chahal, I.A. Salakhov, C. Lacourt, I.I. Semina, R.I. Moustafine, V. V Khutoryanskiy, Crown ethers: Novel permeability enhancers for ocular drug delivery?, Mol. Pharm. 14 (2017) 3528-3538. doi:10.1021/acs.molpharmaceut.7b00556.

[38] K. Al Khateb, E.K. Ozhmukhametova, M.N. Mussin, S.K. Seilkhanov, T.K. Rakhypbekov, W.M. Lau, V. V Khutoryanskiy, In situ gelling systems based on Pluronic F127/Pluronic F68 formulations for ocular drug delivery, Int. J. Pharm. 502 (2016) 70-79. doi:10.1016/j.ijpharm.2016.02.027. 
[39] E. Meaurio, L. Cesteros, L.G. Parada, I. Katime, Blends of poly(mono N-alkyl itaconates) with tertiary polyamides: Specific interactions and thermal degradation, Polym. J. 36 (2004) 84-90. doi:10.1295/polymj.36.84.

[40] L.G. Parada, E. Meaurio, L.C. Cesteros, I. Katime, Miscibility behaviour in blends of copolymers of vinyl alcohol with poly(ethyloxazoline), Macromol. Chem. Phys. 199 (1998) 1597-1602. doi:10.1002/(SICI)1521-3935(19980801)199:8<1597::AIDMACP1597>3.3.CO;2-W.

[41] S.H. Goh, S.Y. Lee, X. Zhou, K.L. Tan, Miscibility and specific interactions in two polyelectrolyte/poly(2- ethyl-2-oxazoline) blend systems, Polymer (Guildf). 40 (1999) 26672673. doi:10.1016/S0032-3861(98)00501-1.

[42] M. Maldonado-Santoyo, C. Ortíz-Estrada, G. Luna-Bárcenas, I.C. Sanchez, L.C. Cesteros, I. Katime, S.M. Nuño-Donlucas, Miscibility behavior and hydrogen bonding in blends of poly(vinyl phenyl ketone hydrogenated) and poly(2-ethyl-2-oxazoline), J. Polym. Sci. Part B Polym. Phys. 42 (2004) 636-645. doi:10.1002/polb.10758.

[43] I. Leceta, P. Guerrero, I. Ibarburu, M.T. Dueñas, K. de la Caba, Characterization and antimicrobial analysis of chitosan-based films, J. Food Eng. 116 (2013) 889-899. doi:https://doi.org/10.1016/j.jfoodeng.2013.01.022.

[44] J. Bonilla, E. Fortunati, L. Atarés, A. Chiralt, J.M. Kenny, Physical, structural and antimicrobial properties of poly vinyl alcohol-chitosan biodegradable films, Food Hydrocoll. 35 (2014) 463-470. doi:https://doi.org/10.1016/j.foodhyd.2013.07.002.

[45] C.L. Silva, J.C. Pereira, A. Ramalho, A.A.C.C. Pais, J.J.S. Sousa, Films based on chitosan polyelectrolyte complexes for skin drug delivery: Development and characterization, J. Memb. Sci. 320 (2008) 268-279. doi:https://doi.org/10.1016/j.memsci.2008.04.011.

[46] A. Colombo, F. Gherardi, S. Goidanich, J.K. Delaney, E.R. de la Rie, M.C. Ubaldi, L. Toniolo, R. Simonutti, Highly transparent poly(2-ethyl-2-oxazoline)-TiO2 nanocomposite coatings for the conservation of matte painted artworks, RSC Adv. 5 (2015) 84879-84888. 
[47] A. Pawlak, M. Mucha, Thermogravimetric and FTIR studies of chitosan blends, Thermochim. Acta. 396 (2003) 153-166. doi:https://doi.org/10.1016/S0040-6031(02)005233.

[48] T. Wanjun, W. Cunxin, C. Donghua, Kinetic studies on the pyrolysis of chitin and chitosan, Polym. Degrad. Stab. 87 (2005) 389-394. doi:https://doi.org/10.1016/j.polymdegradstab.2004.08.006.

[49] E. Beruhil Adatoz, S. Hendessi, C.W. Ow-Yang, A.L. Demirel, Restructuring of poly(2ethyl-2-oxazoline)/tannic acid multilayers into fibers, Soft Matter. 14 (2018) 3849-3857. doi:10.1039/C8SM00381E.

[50] J. Yin, K. Luo, X. Chen, V. V Khutoryanskiy, Miscibility studies of the blends of chitosan with some cellulose ethers, Carbohydr. Polym. 63 (2006) 238-244. doi:10.1016/J.CARBPOL.2005.08.041.

[51] A. Shubha, S.R. Manohara, L. Gerward, Influence of polyvinylpyrrolidone on optical, electrical, and dielectric properties of poly(2-ethyl-2-oxazoline)-polyvinylpyrrolidone blends, J. Mol. Liq. 247 (2017) 328-336. doi:https://doi.org/10.1016/j.molliq.2017.09.086.

[52] H. Fael, C. Ràfols, A.L. Demirel, Poly(2-ethyl-2-oxazoline) as an alternative to poly(vinylpyrrolidone) in solid dispersions for solubility and dissolution rate enhancement of drugs, J. Pharm. Sci. 107 (2018) 2428-2438. doi:https://doi.org/10.1016/j.xphs.2018.05.015.

[53] H. Abdelkader, B. Pierscionek, R.G. Alany, Novel in situ gelling ocular films for the opioid growth factor-receptor antagonist-naltrexone hydrochloride: Fabrication, mechanical properties, mucoadhesion, tolerability and stability studies, Int. J. Pharm. 477 (2014) 631642. doi:https://doi.org/10.1016/j.ijpharm.2014.10.069.

[54] H.S. Mahajan, S.R. Deshmukh, Development and evaluation of gel-forming ocular films based on xyloglucan, Carbohydr. Polym. 122 (2015) 243-247. doi:https://doi.org/10.1016/j.carbpol.2015.01.018. 
[55] S. Karki, H. Kim, S.-J. Na, D. Shin, K. Jo, J. Lee, Thin films as an emerging platform for drug delivery, Asian J. Pharm. Sci. 11 (2016) 559-574. doi:https://doi.org/10.1016/j.ajps.2016.05.004.

[56] O. V Khutoryanskaya, P.W.J. Morrison, S.K. Seilkhanov, M.N. Mussin, E.K. Ozhmukhametova, T.K. Rakhypbekov, V. V Khutoryanskiy, Hydrogen-bonded complexes and blends of poly(acrylic acid) and methylcellulose: Nanoparticles and mucoadhesive films for ocular delivery of riboflavin, Macromol. Biosci. 14 (2014) 225-234. doi:10.1002/mabi.201300313.

[57] G. de O. Fulgêncio, F.A.B. Viana, R.R. Ribeiro, M.I. Yoshida, A.G. Faraco, A. da S. CunhaJúnior, New mucoadhesive chitosan film for ophthalmic drug delivery of timolol maleate: In vivo evaluation, J. Ocul. Pharmacol. Ther. 28 (2012) 350-358. doi:10.1089/jop.2011.0174.

[58] R.M.D. Byrro, G. de Oliveira Fulgêncio, A. da Silva Cunha, I.C. César, P.R. Chellini, G.A. Pianetti, Determination of ofloxacin in tear by HPLC-ESI-MS/MS method: Comparison of ophthalmic drug release between a new mucoadhesive chitosan films and a conventional eye drop formulation in rabbit model, J. Pharm. Biomed. Anal. 70 (2012) 544-548. doi:https://doi.org/10.1016/j.jpba.2012.05.003.

[59] G. de Oliveira Fulgêncio, F.A.B. Viana, R.O.S. Silva, F.C.F. Lobato, R.R. Ribeiro, J.R. Fanca, R.M.D. Byrro, A.A.G. Faraco, A. da Silva Cunha-Júnior, Mucoadhesive chitosan films as a potential ocular delivery system for ofloxacin: preliminary in vitro studies, Vet. Ophthalmol. 17 (2014) 150-155. doi:10.1111/vop.12140.

[60] K. Hermans, D. Van den Plas, S. Kerimova, R. Carleer, P. Adriaensens, W. Weyenberg, A. Ludwig, Development and characterization of mucoadhesive chitosan films for ophthalmic delivery of cyclosporine A, Int. J. Pharm. 472 (2014) 10-19. doi:https://doi.org/10.1016/j.ijpharm.2014.06.017.

[61] P. Tonglairoum, R.P. Brannigan, P. Opanasopit, V. V. Khutoryanskiy, Maleimide-bearing nanogels as novel mucoadhesive materials for drug delivery, J. Mater. Chem. B. 4 (2016) 
643 [62] O.M. Kolawole, W.M. Lau, V. V Khutoryanskiy, Chitosan/ $\beta$-glycerophosphate in situ gelling mucoadhesive systems for intravesical delivery of mitomycin-C, Int. J. Pharm. X. 1 (2019) 100007. doi:https://doi.org/10.1016/j.ijpx.2019.100007.

646

[63] S. Rodrigues, M. Dionísio, C.R. López, A. Grenha, Biocompatibility of chitosan carriers with 647 application in drug delivery, J. Funct. Biomater. 3 (2012). doi:10.3390/jfb3030615.

648 